\section{Giant subjects}

Nicholas Fraser

The Dinosauria. Edited by D.B. Weishampel, P. Dodson \& H. Osmólska. University of California Press: 1990. Pp. 733. \$85.

NEXT year sees the 150th anniversary of the 'invention' of the dinosaurs by the eminent English anatomist and palaeontologist, Richard Owen. It was at the British Association meeting of 1841 held in Plymouth that Owen delivered an address of the scientific validity of certain aspects of vertebrate palaeontological research. Although the last decade has witnessed a surge in the publication of academic papers on dinosaurs, the same period has seen an even greater production of popular books which usually concentrate on the visual impact of dinosaur restorations. Although some of these books are excellent and provide the reader with accurate and up-to-date information, too many have relied heavily upon speculation regarding dinosaur lifestyles. The publication of a book dealing with the dinosaurs in a rigorous scientific way is long overdue,

\section{IMAGE UNAVAILABLE FOR COPYRIGHT REASONS}

common-sense approach to speculation regarding the behaviour and physiology of dinosaurs. They do not dismiss the value of speculating on lifestyles of past life forms, but they do advise and emphasize caution. As a result there are no dogmatic claims; instead well balanced ideas are put forwards which are either backed by stable natural laws or are suggested by analogy with present-day land vertebrates.

Although there will inevitably be those who disagree with opinions expressed by the various authors (I admit that I would question some of the hypotheses put forward), the scientific merit of the book is to be highly commended, and all the hard data on dinosaurs are presented. This volume is a landmark in dinosaur research, and although I am sure that The Dinosauria would have met with the approval of Owen, he would surely have wondered why it took so long to produce a book of this calibre. I expect the volume to be the standard academic text on dinosaurs for a considerable length of time, but at the same time I hope we do not have to wait until the 300th celebration of Owen's major contribution to science before it is updated.

Nicholas C. Fraser is at the Virginia Museum of Natural History, 1001 Douglas Avenue, Martinsville, Virginia 24112, USA.

\section{New in paperback}

- The Physiology of Tropical Crop Production by G. R. Squire provides an introduction to the principles of crop physiology in the tropics emphasizing the importance of the physical environment. Published by CAB International, price $£ 13.95 . \$ 24.50$.

- From Longman comes the second edition of the Guidebook to Organic Synthesis by R. K. Mackie, D. M. Smith and R. A. Aitken, which is aimed at all students of this subject. Price is $£ 14.95$.

- Notes in Classical and Quantum Physics covers the fundamental principles of mathematical physics. The book is written by Franco Battaglia and Thomas George and is published by Blackwell, price $£ 19.50$.

- For an overview of complex formation by macrocyclic ligand systems see The Chemistry of Macrocyclic Ligand Complexes by L. F. Lindoy. Published by Cambridge University Press, price $£ 14.95, \$ 24.90$ (also available in hardback, price $£ 45, \$ 69.50$ ).

- South East Asian Development edited by D. J. Dwyer should be of interest to students of geography and developmental studies as well as policy makers. Published by Longman, price $£ 12.95$.

- In Grazing Management: Science into Practice, John Hodgson provides an introduction to the ecology and management of grazing and grassland farming. Published by Longman, price $£ 11.95$.

- Also from Longmans comes Plant Physiology, Biochemistry and Molecular Biology edited by David Denis and David Turpin, which provides an overview of recent advances particularly in the understanding of plant metabolism. Price is $£ 19$. 